\title{
DESIGN AND SIMULATION OF AUTOMATIC SAFETY VEHICLE DRIVING SYSTEM USING ARDUINO UNO
}

\author{
Arivazhagan \\ Department of Electrical \& Computer Engg. \\ Wolaita Sodo University, Wolaita Sodo \\ SNNPR, Ethiopia
}

\author{
Degu Menna \\ Dept. of Electrical \& Computer Engg. \\ Wolaita Sodo University, Wolaita Sodo \\ SNNPR, Ethiopia
}

\author{
Robel \\ Dept. of ECE \\ WSU, Wolaita Sodo \\ SNNPR, Ethiopia
}

\begin{abstract}
Now a days the usage of cars and vehicles has tremendously increased. The spectacular increase of vehicles on the road has been causing a steady growth accident rates on highways. Road accidents, as the name itself suggests, are random events that are caused by the interplay of diverse factors relating to the road and its condition, the road users, the vehicles, and environmental conditions. Invariably, a combination of two or more of these factors may lead to accidents. This has become a major social problem and deserves special attention from the highway and traffic engineers. In order to prevent road accidents and safeguard human life here an intelligent driving system using Arduino is introduced.
\end{abstract}

Keywords-BAC-Blood alcohol concentration, BrAC Breath alcohol concentration, Arduino Uno, rain sensor, A.O.C.S - Automatic over speed control system

\section{INTRODUCTION}

We know that most of the car accidents are occurring due to over speed, carrying overload and drunken driving. Almost all car accident is caused by the drivers. When the car is accelerated at over speed and violation of traffic rules it leads to accidents. More over the car may prone to skid if driver applies sudden break at over speed. The second root cause for the car accident is due to more passenger or carrying overload. The driver cannot effectively control the car/ truck with overload while he is proceeding to cross the bends and curves on the road particularly hills area as well.

Now a days drunken drivers have increased enormously hence number of accidents have relatively increased. To minimize the car/vehicle accident and protect the human life here we have introduced an alcohol sensor MQ-3 that detects the amount of alcohol consumed by the driver. This module is made using Alcohol Gas Sensor MQ3. It is a low cost semiconductor sensor which can detect the presence of alcohol gases at concentrations from $0.05 \mathrm{mg} / \mathrm{L}$ to $10 \mathrm{mg} / \mathrm{L}$. The sensitive material used for this sensor is $\mathrm{SnO} 2$, whose conductivity is lower in clean air. Its conductivity increases as the concentration of alcohol gases increases. It has high sensitivity to alcohol and has a good resistance to disturbances due to smoke, vapor and gasoline. This module provides both digital and analog outputs. MQ3 alcohol sensor module can be easily interfaced with Microcontrollers, Arduino Boards, and Raspberry etc.

This alcohol sensor is suitable for detecting alcohol concentration on our breath, just like our common breathalyzer. It has a high sensitivity and fast response time. Sensor provides an analog resistive output based on alcohol concentration. The drive circuit is very simple.. Here we have used Arduino micro-controller for controlling the motor /engine of the vehicle. According to the data pattern produced at the input port of the micro controller it takes appropriate decision and actuates the vehicle's motor/engine. This is how vehicle control is achieved. The control logic is produced by the program which is written in Arduino programming board. Some time car accident is caused due to heavy rain. In most cases during heavy rain the visual of the road gets decreased due to rain droplets hitting on the forehead glass, fog and dark clouds. To alleviate this problem here water level detector is used to detect the rainfall which is accumulated on the vehicle forehead glass then sensor sends the signal to the micro controller. Now micro controller actuates and enables the wiper motor rotate in a required speed. This is how the wiper moves quickly on the fore head glass and removes rain water. In order to warn the driver and decelerate the car speed, micro controller sends signal to the alarm as well as indicator circuit. After giving caution to the car driver micro controller waits few seconds and verifies that the car/vehicle speed has been reduced by the driver. or else micro controller sends signal to the engine / actuator. Thus speed of the car/vehicle is reduced. Now the car/vehicle goes slowly. Thus car/vehicle safety driving is automatically achieved. 


\section{International Journal of Engineering Applied Sciences and Technology, 2019 Vol. 4, Issue 6, ISSN No. 2455-2143, Pages 41-47 \\ Published Online October 2019 in IJEAST (http://www.ijeast.com)}

\section{PROPOSED METHODOLOGY}

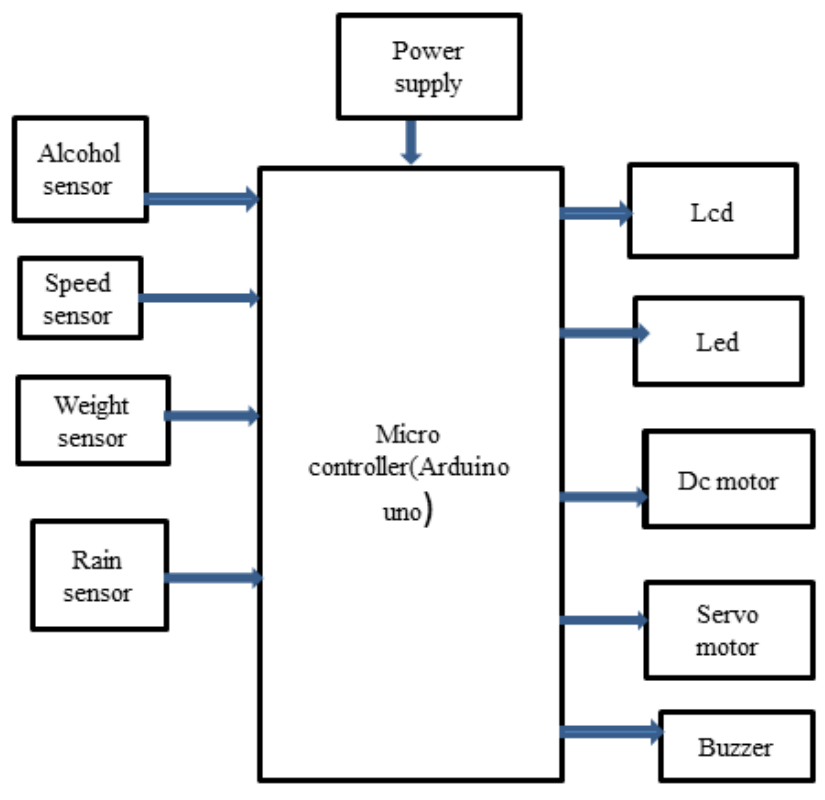

Figure1: Block diagram of the proposed system

The safety in automobiles can also be ensured by introducing A.O.C.S. which stands for automatic over speed control system. It basically controls the speed of the vehicle by continuously checking it through sensors which sends the signal to the input of microcontroller. The microcontroller is a small computer on a single integrated circuit containing a processor core, memory and programmable input/output peripherals. Whenever the speed is increased above the predefined critical speed, the microcontroller sends the signals to the actuators via its output pins. The actuators ie motor /engine speed atomically gets reduced to its safe value. This concept consists of three major systems sensor, microcontroller and actuators (electric DC motor/ engine).. The actuators here are brushless DC motors in which output of microcontroller is connected. By using micro controller speed can be effectively controlled.

\section{A. Component Description}

\section{i.Arduino Micro-controller}

The Arduino Uno is a microcontroller board based on the ATmega328. It has 14 digital input/output pins (of which 6 can be used as PWM out puts), 6 reset button. It contains everything and to support the micro-controller; simply connect it to a computer with a USB cable or power it with an AC-toDC adapter or battery to get started. The Uno differs from all preceding boards in that it does not use the FTDI USB-toserial driver chip.

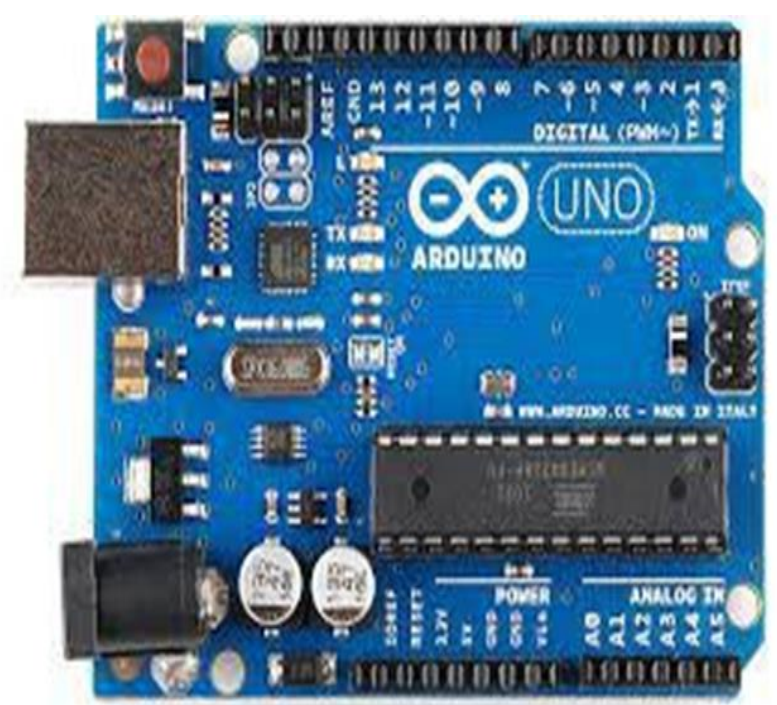

Figure 2: Arduino Uno

\section{ii. Blood Alcohol Content (BAC)}

Case-control study of the relative risk of a crash plotted as a function of the driver's BAC; the latter was derived from analysis of the driver's breath (BrAC 32,100$)$ with an Alcohol Sensor instrument

The relative risk of a crash is only slightly increased (. 1.0) up to a $\mathrm{BAC}$ of $50 \mathrm{mg} / 100 \mathrm{ml}$, but rises to 2.69 times at 80 $\mathrm{mg} / 100 \mathrm{ml}$ and, as the BAC increases further, the risk of a crash increases dramatically. The above study was undertaken in Florida and California, and the results were published recently (Jones, 2008). More recently, two more case control studies of the risk of a traffic crash in relation to the driver's BAC have been done, one in Florida and the other in California (Blomberg et al., 2009). In these studies more reliable breath-alcohol instruments were used and 5,000 crashinvolved drivers were compared with 10,000 non accident control drivers sampled at the same site, the same time of day and weekday, and also the same direction of travel. The relative risk curve is reproduced in Figure 3.1, the arrows showing the risk of a crash at BACs of $20 \mathrm{mg} / 100 \mathrm{ml}, 50$ $\mathrm{mg} / 100 \mathrm{ml}$ and $80 \mathrm{mg} / 100 \mathrm{ml}$. Although the risk of a crash increased compared with non-crash controls, the biggest influence occurs above $80 \mathrm{mg} / 100 \mathrm{ml}$.

The model of alcohol sensor used is MQ-3 alcohol sensor manufactured by Hanwei Manufacturers. This model is suitable to be used in developing devices such as alcohol checker or Breathalyzer (M.Fleischer, 2001).The resistance of the MQ-3 varies with different types of gases at different concentration levels. Therefore, when using this component, calibration is necessary to determine its proper alarm point. Sensitive material of MQ-3 gas sensor is $\mathrm{SnO} 2$, which with lower conductivity in clean air. When the target alcohol gas exist, the sensor's conductivity is higher along with the gas concentration rising. 


\begin{tabular}{|c|c|c|}
\hline Parameter & Value & Unit \\
\hline $\begin{array}{c}\text { Operating } \\
\text { temperature }\end{array}$ & $\begin{array}{c}\text { Room } \\
\text { temperature } 25\end{array}$ & ${ }^{\circ} \mathrm{C}$ \\
\hline $\begin{array}{c}\text { Resistance in air } \\
\text { (typical) }\end{array}$ & 100 & $\mathrm{k} \Omega$ air at room \\
temperature
\end{tabular}

Table 1: Breath alcohol concentration Vs Blood alcohol concentration

\section{B.MQ-3 Alcohol Sensor}

\section{MQ-3 Sensor}

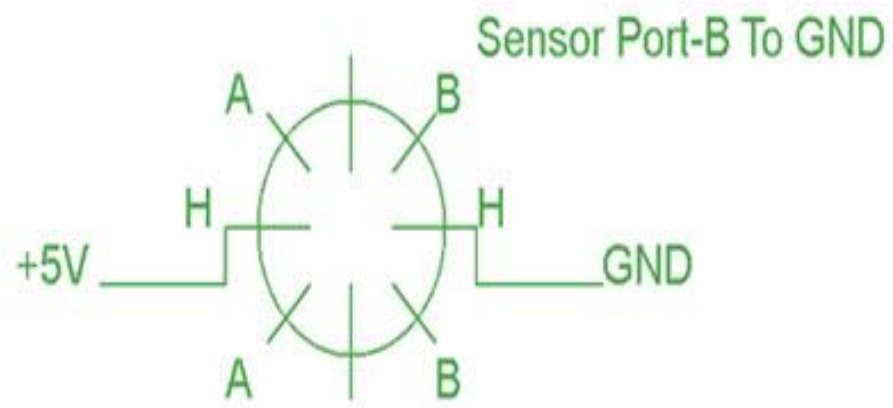

Fig:3 Basic Pin Configuration of MQ-3Alcohol Sensor

Here MQ-3 is used for alcohol detection. It can detect the presence and concentration of alcohol. The MQ-3 alcohol gas sensor consists of total 6-pins including A, H, B and the other three pins are A, H, B out of the total 6-pins we use only 4 pins. The two pins $\mathrm{A}, \mathrm{H}$ are used for the heating purpose and the other two pins are used for the ground and power. There is a heating system inside the sensor, which is made up of aluminium oxide, tin dioxide. It has heat coils to produce heat, and thus it is used as a heat sensor. The above diagram shows the pin diagram and the configuration of the MQ-3 alcohol sensor.

The sensing element used MQ-3 is $\mathrm{SnO}$ 2.It behaves as an insulator but when it is heated it starts behaving as a semiconductor due to the increase in the mobility of electrons (A.C.Romain, 2010). When the alcohol molecule fall on the $\mathrm{SnO} 2$ surface its resistance decreases and the amount of current deliver increases. It is a six pin device, with an integrated heating coil. Sensitivity of $\mathrm{SnO} 2$ is greater at higher temperatures. The supply voltage is $5 \mathrm{~V}$ DC. The output voltage proportional to the alcohol concentration is an analog voltage and is given to the ADC. The sensitive material of MQ-3 gas sensor is $\mathrm{SnO} 2$, which have lower conductivity in clean air. When the target alcohol gas exist, the sensor's conductivity is higher along with the gas concentration rising. Its specifications, features as well as applications include: -

High sensitivity to alcohol (ethanol) and small sensitivity to Benzene.

* Fast response and High sensitivity

* Stable and long life

* Simple drive circuit

* It is used as part of the breathalyzers or breath testers for the detection of ethanol in the human breath.

* They are suitable for alcohol checker, Breath analyzer.

* Vehicle alcohol detector

* Portable alcohol detector

\section{Blood Alcohol Concentration (BAC)}

It is necessary to devise a method to create test gas concentrations to mimic various BAC's. The blood alcohol concentration is defined to be the percentage of alcohol, in grams, in $1000 \mathrm{~mL}$ of blood. Therefore, $0.08 \%$ BAC is $80 \mathrm{mg}$ of alcohol within $100 \mathrm{~mL}$ of blood. Since the sensor detects the presence of alcohol in air, not blood, a relatively constant ratio of 2100:1 was implemented to create these mock-solutions. This ratio comes from a scientifically agreed upon notion that the Breath Alcohol Concentration is defined as the amount of alcohol, in grams, in 2100L of air (Xing-Long, 2006).

\section{Tachometer}

Here Tacho meter is mainly used to monitor the speed of the car/vehicle.

\section{E Liquid Crystal Display}

A liquid crystal display or LCD draws its definition from its name itself. It is combination of two states of matter, the solid and the liquid. LCD uses a liquid crystal to produce visible image.

\section{F. DC Motor}

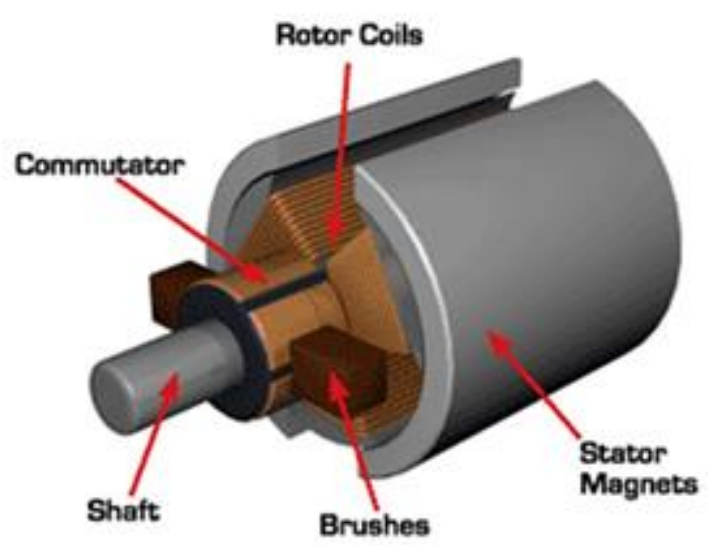

Figure 4: DC motor 


\section{International Journal of Engineering Applied Sciences and Technology, 2019 Vol. 4, Issue 6, ISSN No. 2455-2143, Pages 41-47 \\ Published Online October 2019 in IJEAST (http://www.ijeast.com)}

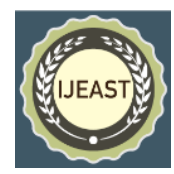

A motor is electrical machine which converts electrical energy in to mechanical energy. The principle of working of a DC motor is that whenever a current carrying conductor is placed in a uniform magnetic field, it experiences a mechanical force the ends of the wire winding are connected to a commutator. The commutator allows each coil to be energized in turn and connects the rotating coils with the external power supply through brushes.

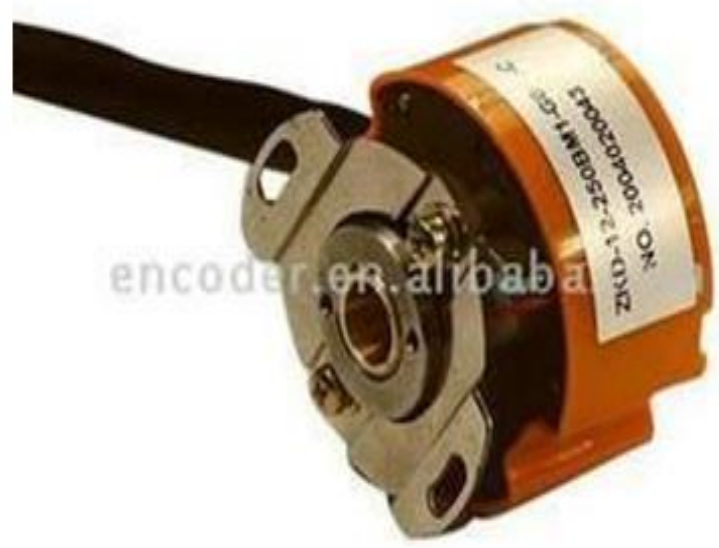

Figure 5: Servo Motor

\section{G. Servo Motor}

Servo motor is a rotary actuator or linear actuator that allows for precise control of angular or linear position, velocity and acceleration. It is mainly used to move the wiper quickly or slowly as per the PWM signal obtained from the micro controller based on the rain fall intensity sensed by rain sensor.

\section{H. Buzzer}

A buzzer or beeper is a signaling device, It most commonly consists of a number of switches or sensors connected to a control unit that determines if and which button is pushed or a preset time has lapsed, and usually illuminates a light on the appropriate button or control panel, and sounds a warning in the form of a continuous or intermittent buzzing or beeping sound.

\section{Water Level Sensor:}

The rain sensor detects precipitation on the windshield using an optoelectronic method of measurement. The sensor element comprises one or more light emitting diodes (transmitters), a prism and a photodiode (receiver). A light beam produced by the light emitting diode passes via a prism to the windshield, is reflected several times by the outer windshield surface and forwarded to the photodiode. The combination of sensor position and dry windshield surface enables maximum reflection of the light beam Raindrops on the windshield change the reflection properties to the extent that all light beams no longer reach their target and are deflected by the drops of water

The greater the intensity of the rain, the less light reaches the photodiode. The evaluation electronics use the irradiance to calculate the amount of rain currently on the windshield and transmit the information needed from the windshield electronics in order to control the wiper speed. The sensor continually takes measurements so that wiping can be individually adapted to the amount of precipitation. If heavy rain or spray from a vehicle driving in front is detected, the system automatically switches from the intermittent setting to the highest wiper setting.

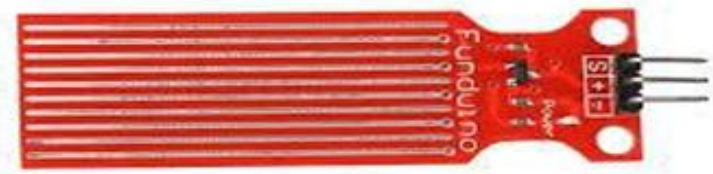

Figure 6: Rain sensor

\section{OPERATION OF SAFETY DRIVING SYSTEM}

\section{Case1: Normal Speed driving condition}

When driver starts the car the micro control unit is automatically turned ON. If car is accelerated with normal speed the micro controller doesn't take any action. Hence LCD display indicates that the car is accelerated with normal speed as shown in figure 7 .

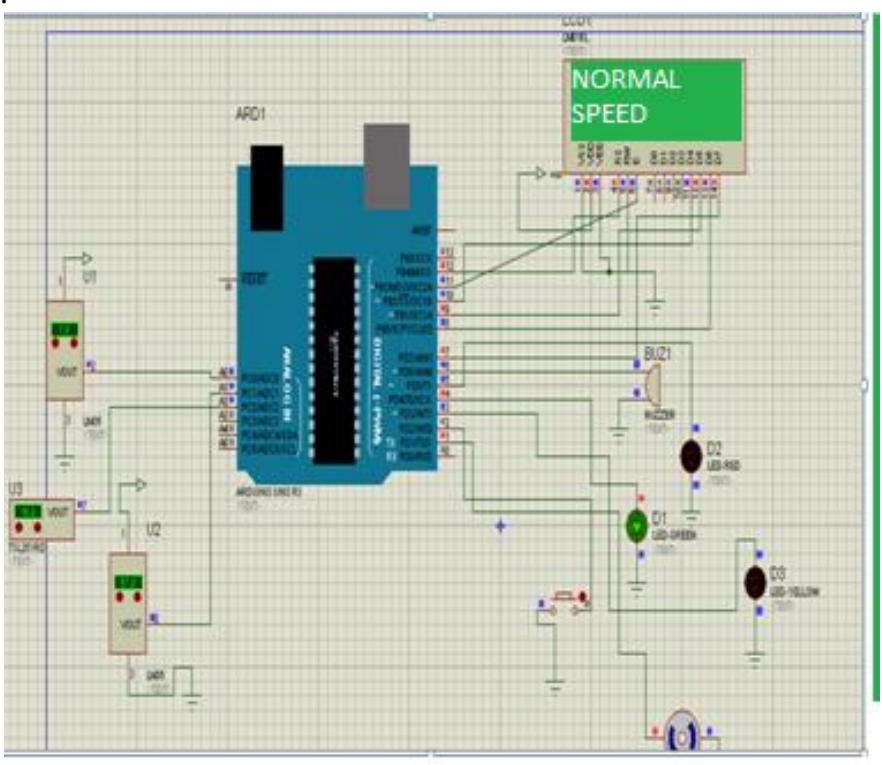

Figure7: Normal Speed driving condition

\section{Case2: Over speed driving condition}

If the car speed is greater than the maximum allowed speed micro controller compares this change in speed with respect to programme algorithm written in micro controller and sends signal to the buzzer. Now buzzer gives sound and warns the car driver to reduce the speed with safe limit and LCD also indicates the current speed of the car as high speed as shown in figure 8. As soon as the car speed is reduced to a safe value the micro controller stops sending signal to buzzer. Now buzzer stops its function. Suppose driver has not responded to the buzzer sound, the micro controller waits for few seconds and verifies either driver changed the car speed to safe value or not. If the car speed is not at all changed within the stipulated time the micro controller now reduces the power of the motor / actuator with help of power modulator. Now the car speed has abruptly reduced to a safe value as shown in figure 8 . 


\section{International Journal of Engineering Applied Sciences and Technology, 2019 Vol. 4, Issue 6, ISSN No. 2455-2143, Pages 41-47 \\ Published Online October 2019 in IJEAST (http://www.ijeast.com)}

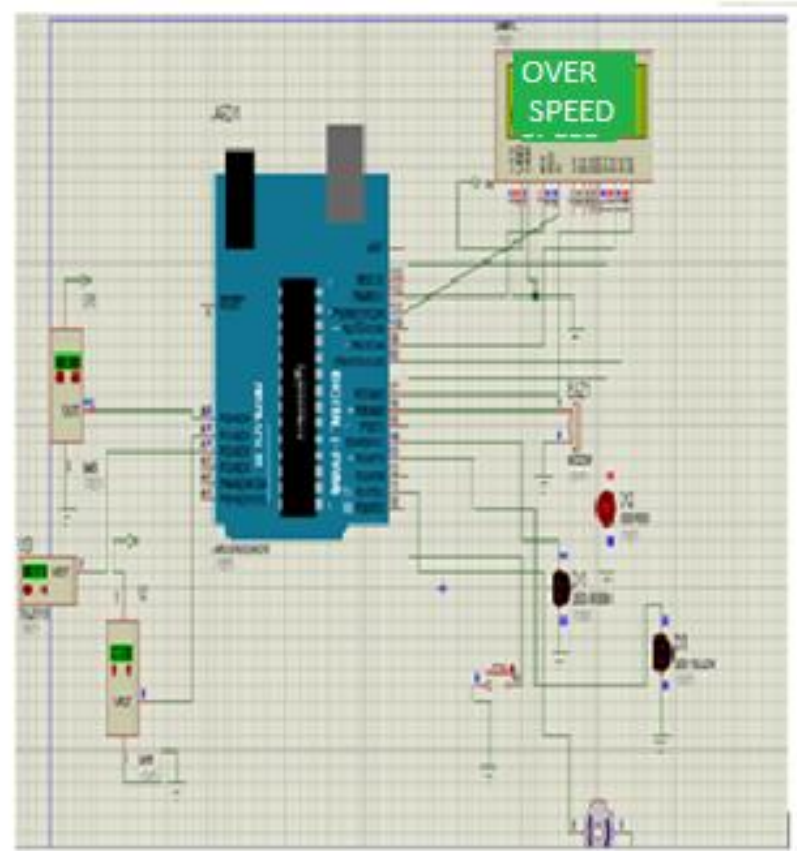

Figure8: Over Speed Driving Condition

Case 3: Normal Load Carrying Condition

While car is carrying the normal load micro controller doesn't receive any signal from load cell. Hence micro controller sends signal to the LCD. Now LCD indicates the driver that the load taken by the car is Normal as shown figure 9 .

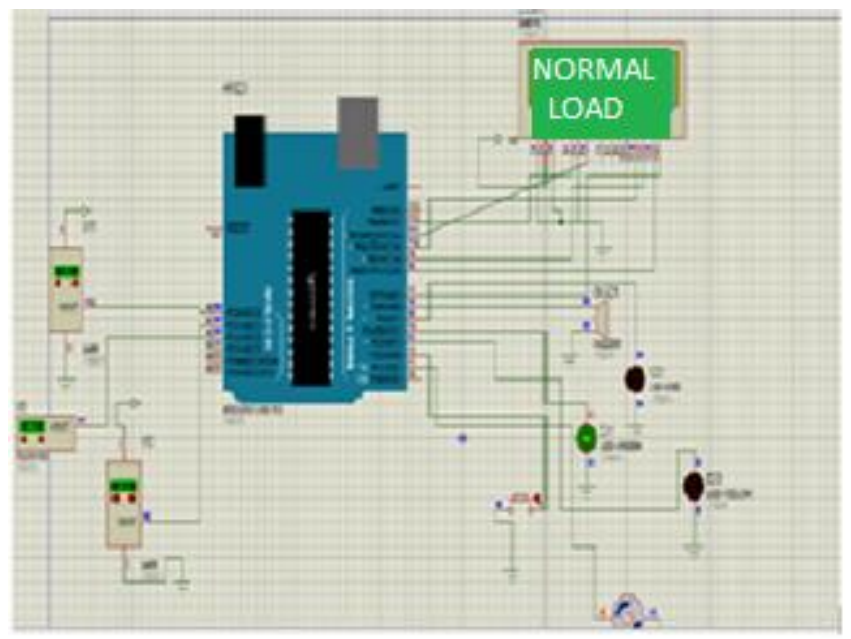

Figure: 9 Normal Load Carrying Condition

\section{Case4: Normal Load Carrying Condition}

When more passengers are travelled in the car beyond the load carrying capacity, Load cell senses this over load and sends signal to micro controller. Based on the progrmme instruction Micro controller indicates the driver about the over load through LCD and buzzer as shown in figure 10

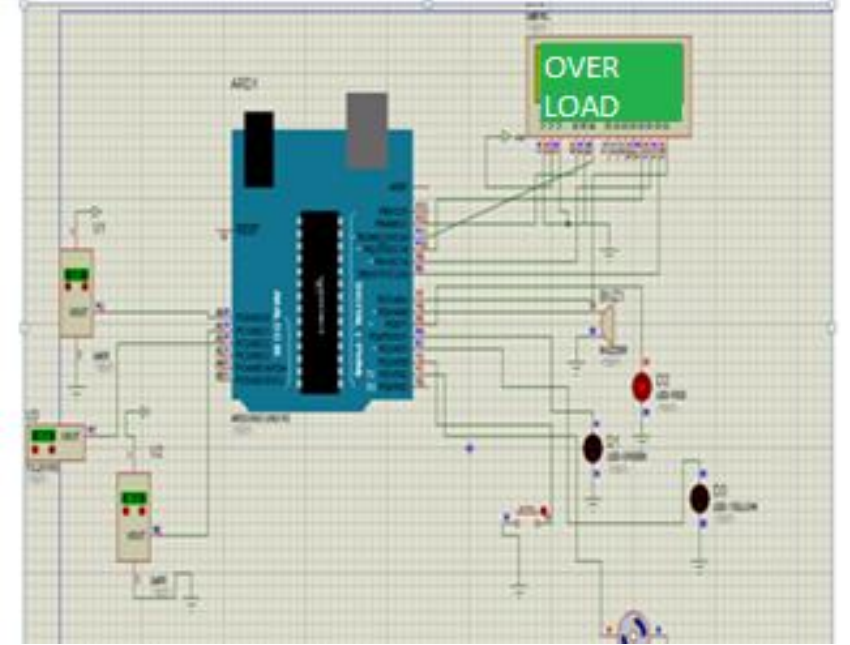

Figure 10: Over Load Carrying Condition

Case 5 driving condition of the driver relative to consume little amount of alcohol

Here if the alcohol concentration of the driver's breath is under the stated value which is from 0.00 to $0.04 \%$ it is equal to the alcohol concentration of the one bottle of bear, there fore driver can drive the car safely. As a result the microcontroller indicates the car driver that "YOU ARE SOBER" as shown in figure 11.

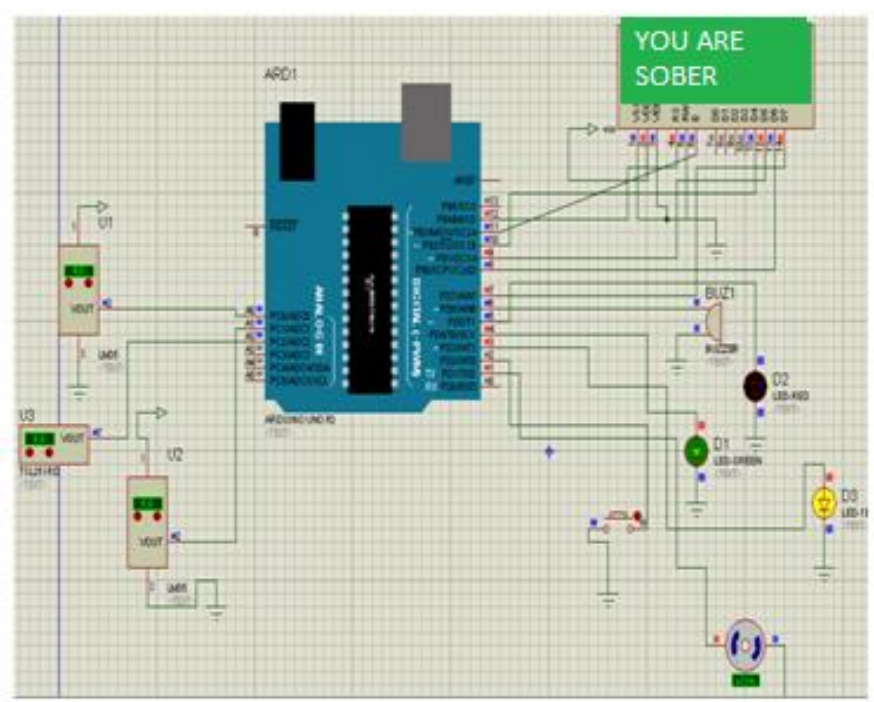

Figure 1 driving condition of the driver relative to consume little amount of alcohol

\section{Case 6: drunken driving condition}

If the car driver has consumed much amount of alcohol the breath alcohol concentration will be more. Under this condition the MQ-3 alcohol sensor senses more alcohol concentration from driver's breath and this sensed signal is sent to micro controller. Now micro controller sends the signal to LCD and buzzer. Now LCD indicates the driver that you are drunk and driving as shown in figure12. Suppose car driver is not in a position to notice the warning signal, after few seconds the micro controller sends a signal to the power modulator hence the electric power/fuel to the actuator is 


\section{International Journal of Engineering Applied Sciences and Technology, 2019 Vol. 4, Issue 6, ISSN No. 2455-2143, Pages 41-47 \\ Published Online October 2019 in IJEAST (http://www.ijeast.com)}

gradually turned off. Thus the car is safely stopped and human life is saved.

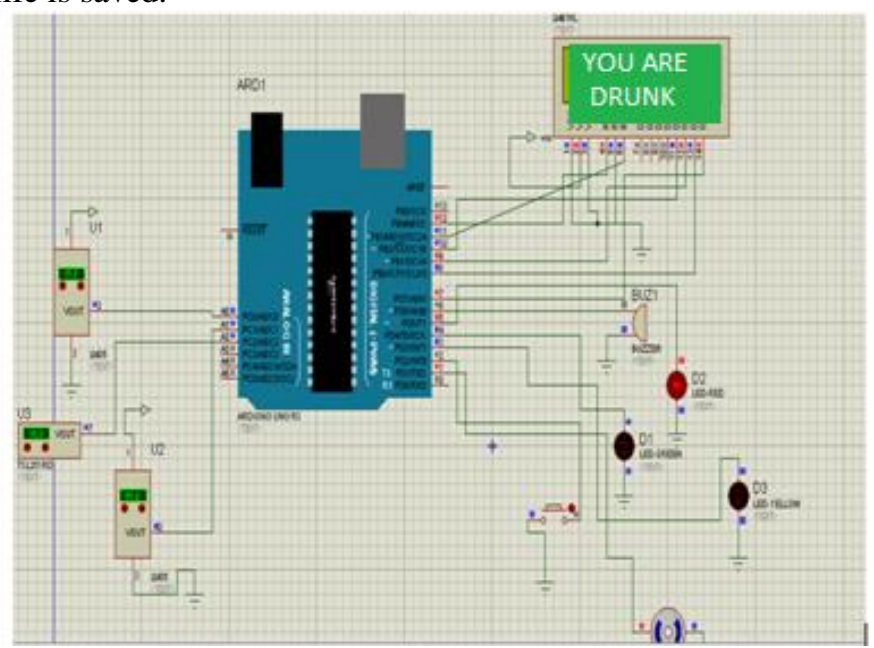

Figure12: Drunken driving conditions

\section{Case 7: When there is no rain}

If it is not raining and there is no rain fall, the rain sensor won't send any signal to micro controller. Under this condition servo motor is turned off and LCD indicates that "NO RAIN" as shown in figure13.

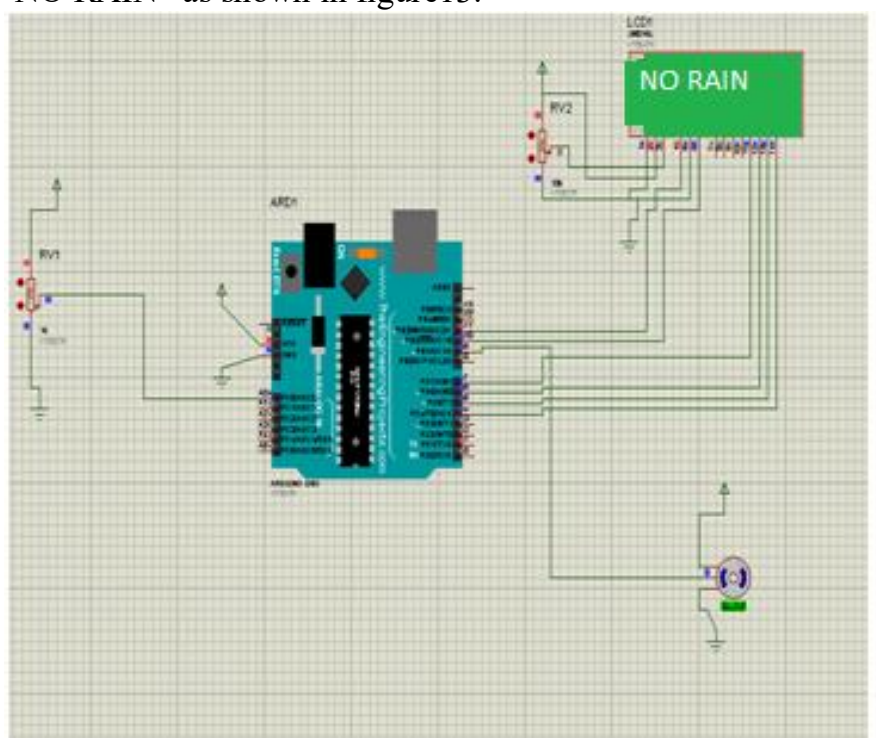

Figure13: When there is no rain

Case 8: When rain begins and rainfall intensity changes

The servo motor will increase speed of rotation when rainfall intensity moves from Low to High. There are 3 speeds preset for - Low, Medium and High intensity. When rainfall intensity decreases, the speed of rotation will decrease automatically. The status message on LCD module will change according to rainfall intensity as follows. Low from 10 to 34 , medium from 35 to 49 and high rain fall intensity above 50.

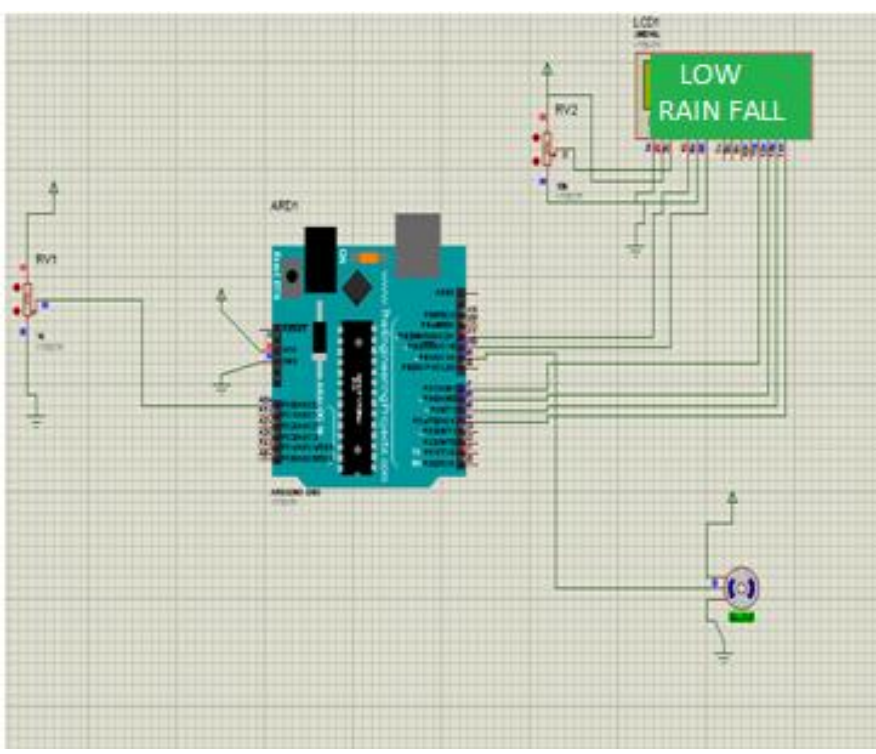

Figure14: Rainfall intensity is low

\section{CONCLUSION}

The Arduino based intelligent safety car/vehicle driving system has been designed and simulated. If the cars/vehicles are Produced with innovative technology and fully automated we can totally avoid road accidents and safe guard our valuable human life and enhance the road safety as well. More over this system through which we can enhance the safety, security and driving efficiency and this system helps us to reach our destination within the stipulated time.

\section{REFERENCES}

[1]. M. Kousikan, and M. Sundaraj (2014) "AUTOMATIC DRUNKEN DRIVE PREVENTION SYSTEM" International sJournal of Students Research in Technology \& Management Vol 2 (02), , ISSN 2321-2543, pg. 74-77.

[2]. Rubini.R, et al (2015) "alerting, recording and reporting system for over speed violation management using Zigbee transmitter" International journal of Engineering Research and Technology volume 2

[3]. S.P. Bunker, etal (2014)“a real-time online safety prototype that controls the vehicle speed under driver fatigue". Vol.46, pp.295-335

[4]. Nimmy James, Aparna C and etal (2014) "Alcohol Detection System'International Journal of Research in Computer andCommunication Technology, Vol 3, Issue 1

[5]. G.Sathya, et (2009) "identifying location using GPRS 3G TECHNOLOGY" International journal of Engineering \&Technology Volume 11

[6]. JyotikaKapur et al dealing with India there has been an increase of $17.4 \%$ in the total number of road accidents during the period of 2011-2012.

[7]. N.M.Z. Hashim, (2014) "Smart wiper control system". International Journal of Computational Engineering Research (IJCER), ISSN (e): 2250 - 3005, Vol, 04, Issue

[8]. Rahul Sindhwan, (2013) " Factors affecting the automatic rain sensing wiper system". International Journal of Scientific \& Engineering Research, Volume 4, Issue 10, ISSN 22295518 . 
[9].Scott A Vandam,"Windshield wiper rain sensor system". International Journal of Innovative Research in Science, Engineering and Technology, Volume 3(1), ISSN: 2394-9333 https://www.arduino.cc/en/main/arduino Uno Board.

[10].TempTrak, (2013) "700 MHz Temperature / Humidity Transmitter," Retrieved from: http://www.cooperatkins.com/Products/TempTrak/900_MHz_ Temperature_Humidity_Transmitter_10071/

[11] Bassem, H., Berssenbrugge, J., Al Qaisi, I., Stocklein, J., (2013) Reconfigurable driving simulator for testing and training of advanced driver assistance systems. IEEE International Symposium on Assembly and Manufacturing, pp. 337-339.

[12] Bifulcoa, G., Pariotaa, L., Brackstioneb, M., Mcdonald, M., (2013) Driving behaviour models enabling the simulation of Advanced Driving Assistance Systems: revisiting the Action Point paradigm. Transportation Research Part C: Emerging Technologies, v. 36, pp. 352-366.

[13] Broggi A., Bertozzi M., Fascioli A., et al. (1999) The ARGO Autonomous Vehicles Vision and Control Systems, International Journal of Intelligent Control and Systems, Vol. 3-4, p 409-441.

[14] Ku, M.Y., Chiu, C.C., Chen, H.T., Hong, S.H. (2008)Visual motorcycle detection and tracking algorithms," WSEAS Transactions on Electronics, v.5(4), pp. 121-131. [15] Liu, G., Wörgötter, F., Markeli, I. 2013. Stochastic Lane Shape Estimation Using Local Image Descriptors.

[16] Maag, C. (2012) Studying effects of advanced driver assistance systems (ADAS) on individual and group level using multi-driver simulation. Intelligent Transportation Systems Magazine, v.4 (3), pp. 45-54. 